\title{
Dose-finding and 24-h monitoring for efficacy and safety of aerosolized Nacystelyn in cystic fibrosis
}

\author{
E.M. App*, D. Baran", I. Dab", A. Malfroot ${ }^{\Uparrow}$, M. Coffiner ${ }^{+}$, F. Vanderbist ${ }^{+}$, M. King $^{\S}$
}

Dose-finding and 24-h monitoring for efficacy and safety of aerosolized Nacystelyn in cystic fibrosis. E. M. App, D. Baran, I. Dab, A. Malfroot, M. Coffiner, F. Vanderbist, M. King. (C) ERS Journals Ltd 2002.

ABSTRACT: The aim of the present studies was to investigate the tolerability and activity of a novel mucolytic drug, Nacystelyn (NAL), for the treatment of cystic fibrosis (CF) lung disease.

In study 1 , involving $10 \mathrm{CF}$ patients, the main objective was to determine the tolerability and potential efficacy of a range of single doses of NAL in comparison to a placebo, in order to establish an optimal dose for further testing. On five consecutive scheduled treatment days, patients inhaled either from two $(4 \mathrm{mg})$ to eight puffs $(16 \mathrm{mg})$ of a single dose of NAL from the range, administered in an open-label fashion, or 12 puffs of active NAL (24 mg) versus 12 puffs of placebo, administered in a randomized double-blind fashion. Pulmonary function data were unaffected and clinically-adverse effects were limited to wheezing in some patients that inhaled 12 puffs of either placebo or active drug. Subsequent rheological analysis of their sputum showed a dose-dependent decrease in sputum viscoelasticity, accompanied by a decrease in sputum solids content and an increase in chloride and sodium concentrations.

In study 2, involving $12 \mathrm{CF}$ patients, the clinical safety and mucolytic activity of a single dose of NAL was monitored over $24 \mathrm{~h}$. On different scheduled treatment days, 7 days apart, patients inhaled a single dose of 12 puffs of active NAL ( $24 \mathrm{mg}$ ) or 12 puffs of placebo drug in a randomized, double-blind sequence, with sputum samples taken at intervals before and after inhalation. Mucus rigidity decreased following NAL inhalation, with the maximum effect observed at $4 \mathrm{~h}$; the 1-, 2- and 4-h NAL rheology results were significantly different from placebo. No adverse effects were observed.

The drug was well tolerated in both studies. Sputum results were predictive of improved clearability by ciliary and cough transport mechanisms.

Eur Respir J 2002; 19: 294-302.
*CF-Outpatient Clinic, Albert-Ludwigs University, Freiburg, Germany. ${ }^{\#}$ Service de Pneumologie, Dépt de Mucoviscidose, Erasmus University Hospital, Université Libre de Bruxelles (ULB), Brussels, Belgium. Kinderpneumologie, Academic Hospital, Vrije Universiteit Brussel (VLB), Brussels, Belgium. ${ }^{+}$Laboratoires SMB \& Galephar, Brussels, Belgium. ${ }^{\$}$ Pulmonary Research Group, University of Alberta, Edmonton, Canada.

Correspondence: M. King, 173 HMRC, University of Alberta, Edmonton, AB, T6G 2S2, Canada.

Fax: 17804924878

E-mail: malcolm.king@ualberta.ca

Keywords: Airway clearance, cystic fibrosis, epithelial ion transport, mucolytic therapy, protease inhibitors, sputum rheology

Received: March 162001

Accepted after revision September 19 200

This study was supported by SMB \& Galephar, and in part by the Canadian CF Foundation.
Cystic fibrosis (CF) is a chronic, progressive and generally fatal genetic disease caused by mutations in the gene that codes for the CF transmembrane regulator protein [1]. The main physiological defect is related to abnormal transepithelial sodium and chloride transport. In most patients, this leads to raised levels of chloride in sweat $\left(>60 \mathrm{mmol} \cdot \mathrm{L}^{-1}\right.$, with chloride higher than sodium) [2] and reduced chloride permeability in airway and intestinal epithelia. These factors cause most of the clinical problems, although the exact mechanisms are still unclear. In general, the exocrine glands are dysfunctional, resulting in viscous secretions of low water content. These viscous secretions are poorly cleared, especially in the lung [3], leading both to obstruction of the airways and recurrent and chronic lung infections. The cycle of chronic infection causes early-sustained and severe inflammatory reactions [4], leading to progressive lung damage, eventual respiratory failure and, ultimately, death.

Nacystelyn (NAL), a salt derivative of $N$-acetylcysteine (ACC) and lysine, is a mucoactive agent developed for the treatment of impaired mucociliary clearance and chronic mucus retention in CF. NAL has been shown to have direct mucolytic activity approximately equal to the sum of the activities of its two components, ACC and lysine [5]. App et al. [6] and DAsGuPTA and KING [7] found NAL to be effective in reducing the viscoelasticity of $\mathrm{CF}$ sputum in the $10^{-4} \mathrm{M}$ range. Through use of spinnability as a rheological measure, DASGUPTA and KING [7] also found that NAL combined synergistically with recombinant human deoxyribonuclease (rhDNase; Pulmozyme $\mathbb{R}$, Genentech Inc., San Francisco, CA, USA) in reducing the viscoelasticity of CF sputum. In addition to this direct mucolytic activity, NAL in vivo appears to increase the transepithelial potential difference, causing a stimulation of chloride transport, which induces water movement into the epithelial lining fluid and further enhances the fluidification of the mucus [8-10]. This important additional effect of NAL in vivo is believed to be due to its lysine component [11].

The almost neutral $\mathrm{pH}$ of NAL (negative logarithm of the acid ionization constant $\left.\left(\mathrm{pK}_{\mathrm{a}}\right)=6.2\right)$, in contrast to the high acidity of its parent molecule ACC $\left(\mathrm{pK}_{\mathrm{a}}=2.2\right)$, has eliminated the need for a buffering 
agent and has led to the development of a metereddose inhaler (MDI), which does not produce an increase in airway responsiveness [12]. Besides its mucolytic activity and chloride-transport stimulation, NAL appears to play a role in alleviating and/or preventing oxidative lung damage caused by an active inflammatory response [13-16] and in changing the protease-to-antiprotease balance in bronchial secretions to antiprotease $[6,17,18]$.

On the basis of these observations, it appears that administration of NAL may be a promising therapeutic approach to the treatment of $\mathrm{CF}$. The authors therefore decided to perform an initial pilot clinical study (study 1), with the main objective of determining the tolerability and potential efficacy of several different single doses of NAL in comparison to a placebo, in order to establish an optimal dose that could be be tested in further clinical studies. This study was carried out in CF patients with mild-tomoderate lung dysfunction. Evidence of activity of NAL was determined by observations of sputum rheology, consistent with a mucolytic effect.

In light of the favourable results from the dosefinding study, the highest single dose tested (i.e. $24 \mathrm{mg}$ of NAL) was retained for further investigation. The main objective of the second pilot study (study 2) was to determine the duration of efficacy and tolerability of this single dose of NAL in comparison to a placebo in a group of patients with CF lung disease, in order to establish an optimal dosing schedule that could be tested in further clinical studies.

\section{Methods}

\section{Study 1: dose-finding study}

From those attending the $\mathrm{CF}$ Clinic of Erasmus Hospital, Brussels, Belgium, $10 \mathrm{CF}$ patients (six males, four females) aged 15-31 yrs, were selected at a run-in visit, 1 week before entry into the study and according to the inclusion and exclusion criteria. They all signed an informed consent form, with the signature of a witness. The study was approved by the Ethical Committee of Erasmus University Hospital, Université Libre de Bruxelles (ULB) in Brussels, Belgium.

Patients were selected if they had CF with mildto-moderate lung function impairment, were aged $>7 \mathrm{yrs}$, and were diagnosed as having the disease from a combination of medical history, clinical examination, chest radiograph, and abnormal sweat test (by iontophoresis with pilocarpine). Patients were excluded from participation in the study if they: had severe respiratory disease (forced expiratory volume in one second (FEV1) $<30 \%$ predicted); had a recent history of an acute respiratory episode within 2 weeks before the study; were unable to stop using antibiotics, bronchodilators, mucolytics or expectorant drugs within 1 week prior to their first intake of the study drug; had a history of allergy to ACC or related drugs; were unable to use an MDI correctly; were aged $<7 \mathrm{yrs}$; or refused to give signed written consent. In addition, female patients who may have been pregnant, pregnant women and nursing mothers were all refused entry into the study.

Study design. The study was designed to look for an optimal single dose of NAL, which may be potentially active and well tolerated in mild-to-moderate $\mathrm{CF}$ patients.

NAL was administered by MDI (Armstrong Laboratories, part of Medeva Inc., West Roxbury, MA, USA). Inhalation was made via a Volumatic spacer (Allen \& Hanburys, Uxbridge, Middlesex, UK), which delivers a respirable fraction (weight fraction of particles $<4.7 \mu \mathrm{m}$ ) of about one-tenth the nominal dose [19]. The doses were delivered to the patient puff-by-puff, using a deep inhalation technique, with the patient waiting $\sim 30$ s between puffs.

The NAL and placebo metered-dose inhalants were supplied by Laboratoires SMB \& Galephar S.A. (Brussels, Belgium). The placebo consisted of a surfactant, sorbitone trioleate, and a mixture of freons as propellants. The NAL inhalant contained the same ingredients as were in the placebo formulation, plus $6.7 \mathrm{mg}$ of L-lysine ACC (Nacystelyn, Moehs SA, Rubi, Barcelona, Spain) per $100 \mathrm{mg}$ of propellants. The MDI was designed to deliver 150 puffs per container, each puff containing $2 \mathrm{mg}$ of active ingredient. In connection with the present study, the particle size distribution of NAL administered from the inhaler was measured using an Andersen Cascade Impactor (Andersen plc, Nottingham, UK), which was tested as described in the literature [20].

During the run-in visit, a complete medical history was taken, including the patient's genotype (when available), general physical health (including tiredness, appetite and weight) and dyspnoea evaluation (all rated on a numerical scale of $0-4$ (0: best score, 4: worst score)), and concomitant medications. A physical exam, including a pulmonary and cardiological exam, was also performed. Pulmonary function tests (whole body plethysmography; Jaeger Instruments, Würzburg, Germany) including vital capacity (VC), FEV1, Tiffeneau ratio (FEV1/VC), specific airway resistance ( $\mathrm{s} R \mathrm{aw}$ ), peak expiratory flow (PEF) and arterial oxygen saturation $\left(\mathrm{Sa}_{2} \mathrm{O}_{2}\right.$; Ohmeda Biox 3700 pulse oximeter, Louisville, KY, USA) were all administered. A chest radiograph was also taken (if unavailable from the last 6 months) and scored from 0-25 according to the Brasfield scoring technique [21]. A washout period of antibiotics, bronchodilators, mucolytics and expectorant drugs was enforced from 1 week prior to their first intake of study drug.

Patients then returned to the clinic to receive their study treatment over five visit days, which, in most instances, were consecutive. The study treatment consisted of a series of randomly-administered single doses of either $4 \mathrm{mg}$ (two puffs), $8 \mathrm{mg}$ (four puffs) or $16 \mathrm{mg}$ (eight puffs) of active drug administered in an open-label fashion, or $24 \mathrm{mg}$ (12 puffs) of active drug or 12 puffs of placebo drug administered in a randomized double-blind fashion.

The time interval between treatment doses was programmed to be $\sim 24 \mathrm{~h}$; administration was always in the morning, at the same time each day. During each of the five study visits and $\geqslant 15 \mathrm{~min}$ before the 
inhalation of the study drug, the patient was questioned about general health and any change in concomitant medication. In addition, during each study visit $\geqslant 15 \mathrm{~min}$ before and $\sim 30 \mathrm{~min}$ after inhalation of the study drug, a dyspnoea evaluation, pulmonary function tests, $\mathrm{Sa}_{\mathrm{a}} \mathrm{O}_{2}$ measurements, and a pulmonary and cardiological physical exam were performed on each patient. Any adverse events occurring after inhalation of the study drug were recorded by the clinical investigator.

Sputum samples were also collected, primarily in order to evaluate the rheology, but also to examine the electrolyte content and protease and antiprotease activity. Dental cotton was used on the orifices of salivary ducts to reduce saliva contamination [22]. For each sputum sample collection, a specific technique was employed. The patient was directed to cough into a glass beaker under a physiotherapist's supervision. The first sample was collected $\geqslant 15 \mathrm{~min}$ before inhalation and the second sample $\sim 30 \mathrm{~min}$ after inhalation on each study day. The samples were transferred using tweezers into a $10 \mathrm{~mL}$ test tube and covered immediately with $\sim 0.5 \mathrm{~mL}$ of light paraffin oil (Fisher, Zürich, Switzerland). Each tube was then covered with a screw-top cap, labelled with an alcohol-based colour pen and the label covered with transparent tape. Within $30 \mathrm{~min}$ of collection, it was placed in a deep freezer for storage at $-80^{\circ} \mathrm{C}$. Once all the sputum samples were collected, they were placed in a styrofoam box filled with dry ice and shipped overnight to a specialized laboratory at the University of Grosshadern, Munich, Germany (GSF Hematologicum, E.M. App) for processing and analysis of sputum.

\section{Study 2: 24-h monitoring study}

Twelve CF patients (seven males, five females) ranging from 12-31 yrs were recruited for this study (six were from the Erasmus University Hospital, ULB and the other six were from the Academic Hospital, Vrije Universiteit Brussel (VUB), Brussels, Belgium). Patients (or guardians, if the patient was $<18$ yrs old) all signed an informed consent form. The study was approved by the respective ethics committees of both hospitals. Eligibility criteria were the same as for study 1 .

Study design. The study was designed to look for the duration of activity and the tolerability of a single dose of NAL compared to a placebo in CF patients with mild-to-moderate pulmonary dysfunction. Both NAL and placebo were administered from an MDI (Armstrong Laboratories) identical to that used in study 1; inhalation was again made via a Volumatic spacer (Allen \& Hanburys).

Run-in procedures were the same as in study 1 , with the following additions or variations: rales found on pulmonary auscultation were evaluated on a numerical scale of 0-4 (0: best score, 4: worst score) and wheezing on a scale of $0-2$ (0: best score, 2 : worst score). A chest radiograph was also taken (if unavailable from 1 month prior to entry into the study) and scored 0-25 according to the Brasfield scoring method [21]. A sputum sample was taken (if unavailable from 1 month prior to entry into the study) for semiquantitative bacterial analysis. A washout period of antibiotics (especially inhaled), bronchodilators, mucolytics and expectorant drugs was enforced from $72 \mathrm{~h}$ prior to their first intake of study drug.

In the hospital clinic, patients were then allocated to receive, on two separate days, a single morning dose of either 12 puffs ( $24 \mathrm{mg}$ ) of active drug or 12 puffs of placebo drug in a randomized, double-blind, two-way crossover design. The time interval between the two administrations was 7 days. The order of treatment was randomized and the time of day of therapy was the same for each administration. Each patient was closely monitored for side-effects over a period of $8 \mathrm{~h}$ after dosing and on the morning of the following day, $24 \mathrm{~h}$ after dosing. During each study visit, the patient was questioned about any change in concomitant medication.

Sputum samples were collected $\geqslant 15 \mathrm{~min}$ before inhalation of the dose and 1, 2, 4, 8 and $24 \mathrm{~h}$ afterwards in order to evaluate primarily the rheology, but also the electrolyte content and the protease and antiprotease activity. Placebo data were also examined for evidence of diurnal variability.

\section{Sputum analysis}

Sputum was examined for five properties: rigidity, spinnability, hydration, changes in electrolytes and protease-to-antiprotease activity.

Rheological properties of sputum aliquots were measured by magnetic microrheometry [23, 24]. Approximately $2 \mu \mathrm{L}$ aliquots of sputum were placed in the chamber of the magnetic microrheometer and the rigidity, $\mathrm{G}^{*}$ (mechanical impedance=vector sum of viscosity and elasticity) and loss tangent (viscosity/ elasticity) were determined at low $\left(1 \mathrm{radian}(\mathrm{rad}) \cdot \mathrm{s}^{-1}\right)$ and high $\left(100 \mathrm{rad} \cdot \mathrm{s}^{-1}\right)$ frequencies. These measurement frequencies are used to simulate mucociliary and cough clearance conditions, and thus obtain relevant viscoelasticity. The measured viscoelastic data were expressed as $\log G^{*}$ and $\tan \delta$, and were used to calculate a mucociliary clearability index as well as a cough clearability index from previously established relationships, based on model studies [25].

Spinnability measurements were performed in order to measure the gross elastic deformation capacity, which is important for an effective cough clearance in mucus hypersecretion such as in CF. Spinnability is the thread-forming ability of mucus under the influence of low-speed elastic deformation. The spinnability of CF sputum samples was measured using a filancemeter (Type 04, SEFAM, Nancy, France) [26], modified to accommodate small sample volumes, in which a $20-30-\mu \mathrm{L}$ sputum sample is stretched at a distraction velocity of $10 \mathrm{~mm} \cdot \mathrm{s}^{-1}$. An electrical signal conducted through the mucus sample is interrupted at the point where the mucus thread is broken. The length of this thread is known as the mucus spinnability (measured in $\mathrm{mm}$ ).

A gravimetric method was used to determine the 
Table 1.-Baseline clinical and anthropometrical data: phase 1

\begin{tabular}{|c|c|c|c|c|c|c|c|c|c|}
\hline Patient & Sex & Age yrs & Genotype & XRS & $\mathrm{VC} \%$ pred & FEV1 \% pred & Tiffenau FEV1/VC \% & sRaw & PEF \\
\hline 1 & M & 19 & F508- & 10 & 63 & 35 & 46 & 22.8 & 2.4 \\
\hline 2 & M & 20 & unknown & 12 & 73 & 53 & 60 & 13.2 & 5.3 \\
\hline 3 & M & 31 & F508/F508 & 17 & 97 & 48 & 39 & 29.5 & 5.9 \\
\hline 4 & M & 19 & F508/F508 & 10 & 75 & 60 & 65 & 8.1 & 6.7 \\
\hline 5 & M & 26 & unknown & 16 & 79 & 43 & 44 & 16.2 & 5.6 \\
\hline 6 & $\mathrm{~F}$ & 15 & F508/- & 11 & 77 & 52 & 57 & 15.3 & 3.4 \\
\hline 7 & $\mathrm{~F}$ & 19 & F508/- & 18 & 73 & 42 & 50 & 4.1 & 3.7 \\
\hline 8 & $\mathrm{~F}$ & 20 & unknown & 15 & 81 & 58 & 62 & 10.2 & 4.7 \\
\hline 9 & M & 24 & F508/F508 & 15 & 85 & 40 & 39 & 15.7 & 6.0 \\
\hline 10 & $\mathrm{~F}$ & 17 & unknown & 21 & 102 & 63 & 52 & 5.5 & 7.0 \\
\hline
\end{tabular}

XRS: X-ray score; VC: vital capacity; FEV1: forced expiratory volume in one second; sRaw: specific airway resistance; PEF: peak expiratory flow; \% pred: percentage of predicted; M: male; F: female.

solids content of the sputum in order to evaluate hydration, which may change due to an alteration in epithelial secretory activity, such as an increase in chloride secretion. A Mettler analytical balance (Mettler Toledo, Inc., Columbus, OH, USA) was used to weigh the sputum samples before and after evaporation to dryness in a microwave oven at $750 \mathrm{~W}$ [27].

Electrolyte analysis of sputum aliquots was carried out with atomic emission spectrometry, using an inductive-coupled plasma technique for the analysis of sodium, potassium and calcium. Chloride analysis was then performed with a segmented continuousflow analysis system, where chloride was detected by the formation of azo-complexes. The results were expressed as $\mathrm{mmol} \cdot \mathrm{L}^{-1}$ (wet weight).

Photometric protease activity measurements were performed at $405 \mathrm{~nm}$ light wavelength and expressed as extinction increase $\cdot \mathrm{min}^{-1}$ (i.e. as inhibitor units). The elastase-neutralizing activity of protease inhibitor was determined by pre-incubation of identical amounts of inhibitor and elastase. The remaining inhibitor activity was measured with neutrophil granulocytic elastase as the target enzyme and suc-Lalanyl-L-valyl-4-nitroanilide as a specific chromogenic substrate.

\section{Statistical methods}

Data from each protocol are presented as mean \pm sD. To analyse the significance of the changes in clinical, pulmonary function and sputum parameters, data following therapy were compared with those prior to it. Equality of means was tested by analysis of variance; post hoc analysis of changes from preinhalation values was determined where appropriate by a two-tailed, paired t-test. A p-value of 0.05 was considered statistically significant.

\section{Results}

\section{Study 1: dose-finding study}

Patient characteristics. The age, sex, genotype, radiograph score, and respiratory characteristics of the patients at the pre-inclusion examination are summarized in table 1 . On average, the females were younger (mean age $17.8 \mathrm{yrs}$ ) than the males (23.2 yrs). There were no sex-related differences in pulmonary function when corrected for height and weight. All 10 patients enrolled in this pilot study completed each of the five study days.

Pulmonary function change with Nacystelyn or placebo. Table 2 summarizes the pre- and post-test values of VC, FEV1, FEV1/VC, sRaw, PEF for the 12-puff, 24-mg NAL administration and the 12-puff, randomized, blinded placebo administration. Acute administration of NAL or placebo did not cause significant changes in any of these pulmonary function parameters. Similar findings were obtained for the three lower doses of NAL (4 mg, $8 \mathrm{mg}$, and $16 \mathrm{mg}$ ).

Table 2. - Acute pulmonary function changes with Nacystelyn (NAL) $(24 \mathrm{mg})$ or placebo (PL)

\begin{tabular}{|c|c|c|c|c|c|c|c|c|c|c|}
\hline & \multicolumn{2}{|c|}{$\mathrm{VC} \%$ pred } & \multicolumn{2}{|c|}{ FEV1\% pred } & \multicolumn{2}{|c|}{ FEV1/VC \% } & \multicolumn{2}{|c|}{ sRaw } & \multicolumn{2}{|c|}{ PEF } \\
\hline & Pre & Post & Pre & Post & Pre & Post & Pre & Post & Pre & Post \\
\hline \multicolumn{11}{|l|}{ PL } \\
\hline Mean & 77.70 & 78.40 & 47.70 & 48.50 & 51.9 & 52.1 & 15.35 & 14.24 & 4.42 & 4.31 \\
\hline SD & 15.20 & 13.04 & 10.74 & 14.39 & 9.6 & 11.0 & 10.97 & 9.18 & 1.39 & 1.30 \\
\hline \multicolumn{11}{|l|}{ NAL } \\
\hline Mean & 76.60 & 78.20 & 48.00 & 49.60 & 52.3 & 52.5 & 15.96 & 15.07 & 4.53 & 4.52 \\
\hline SD & 10.75 & 12.87 & 12.00 & 14.50 & 10.0 & 10.2 & 12.29 & 11.56 & 1.13 & 1.30 \\
\hline
\end{tabular}

VC: vital capacity; FEV1: forced expiratory volume in one second; sRaw: specific airway resistance; PEF: peak expiratory flow; $\%$ pred: percentage of predicted. 
Table 3. - Adverse effects/tolerability in dose-finding study

\begin{tabular}{lcc}
\hline Patient no. & Treatment & Adverse effects reported by the clinical investigator \\
\hline 2 & Day 2: placebo 12 puffs & Wheezing \\
& Day 5: active 8 puffs $(16 \mathrm{mg})$ & Wheezing \\
3 & Day 3: active 4 puff $(8 \mathrm{mg})$ & Worsening of dyspnoea \\
& Wheezing \\
5 & Day 5: active 12 puffs $(24 \mathrm{mg})$ & Transitory worsening of dyspnoea (5 min) \\
7 & Day 1: placebo 12 puffs & Wheezing \\
8 & Day 3: placebo 12 puffs & Cough, throat irritation \\
\hline
\end{tabular}

There were no significant differences in pre-aerosol pulmonary function from one study day to the next. Adverse effects were seen in five patients, as noted in table 3. The majority of the adverse events (four of seven) were associated with 12 puffs of the placebo and not with the active drug. On six occasions and in three patients, dyspnoea was reported as improved; for five of these six occasions, NAL had been administered.

Sputum rheology. Figure 1a shows the principal index of mucus rigidity: $\mathrm{G}^{*}$ in dyne $(\mathrm{dyn}) \cdot \mathrm{cm}^{-2}$, as determined by magnetic rheometry at $1 \mathrm{rad} \cdot \mathrm{s}^{-1}$ and expressed on a logarithmic scale $\left(\log G^{*} 1\right)$. The
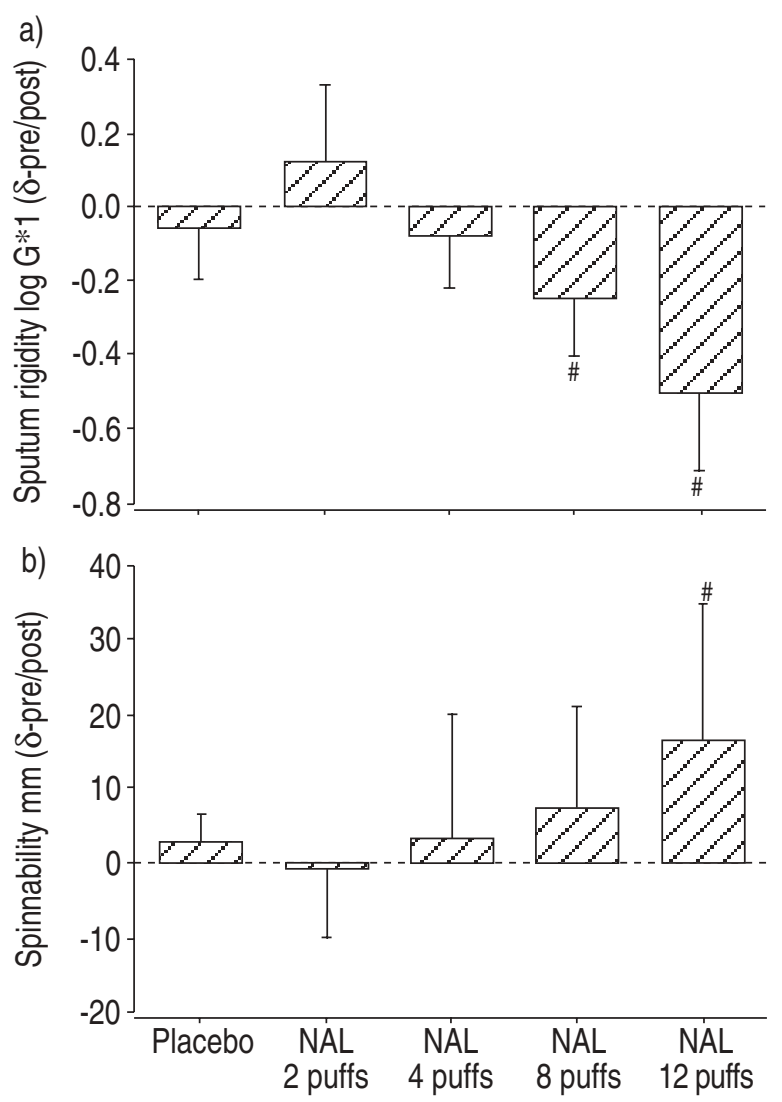

Fig. 1.-a) Nacystelyn (NAL) dose-response of sputum rigidity. Change in sputum rigidity index, $\log \mathrm{G}^{*}$ at 1 radian $(\mathrm{rad}) \cdot \mathrm{s}^{-1}$, as determined by magnetic rheometry versus dose of NAL delivered. b) NAL dose-response relationship for the change in sputum spinnability, obtained by means of a filancemeter. Data are illustrated as mean differences in postinhalation versus pre-inhalation values \pm SEM. \#: statistically significant difference from placebo by paired t-test. differences between $\log \mathrm{G}^{*}$ at 10 and $100 \mathrm{rad} \cdot \mathrm{s}^{-1}$ with NAL dose were negligible. In simple terms, the mucus became less rigid or more deformable, thus benefiting clearability, based on predictions from model studies, as illustrated in figure 2 (mucociliary clearability index and cough clearability index). After eight and 12 puffs of NAL (16 and $24 \mathrm{mg}$ ), sputum viscoelasticity decreased significantly $(\mathrm{p}=0.0081$ and $\mathrm{p}=0.0009$, respectively) and both clearability indices increased significantly.

Figure $1 \mathrm{~b}$ also depicts the dose-response relationship of sputum spinnability, as determined by a
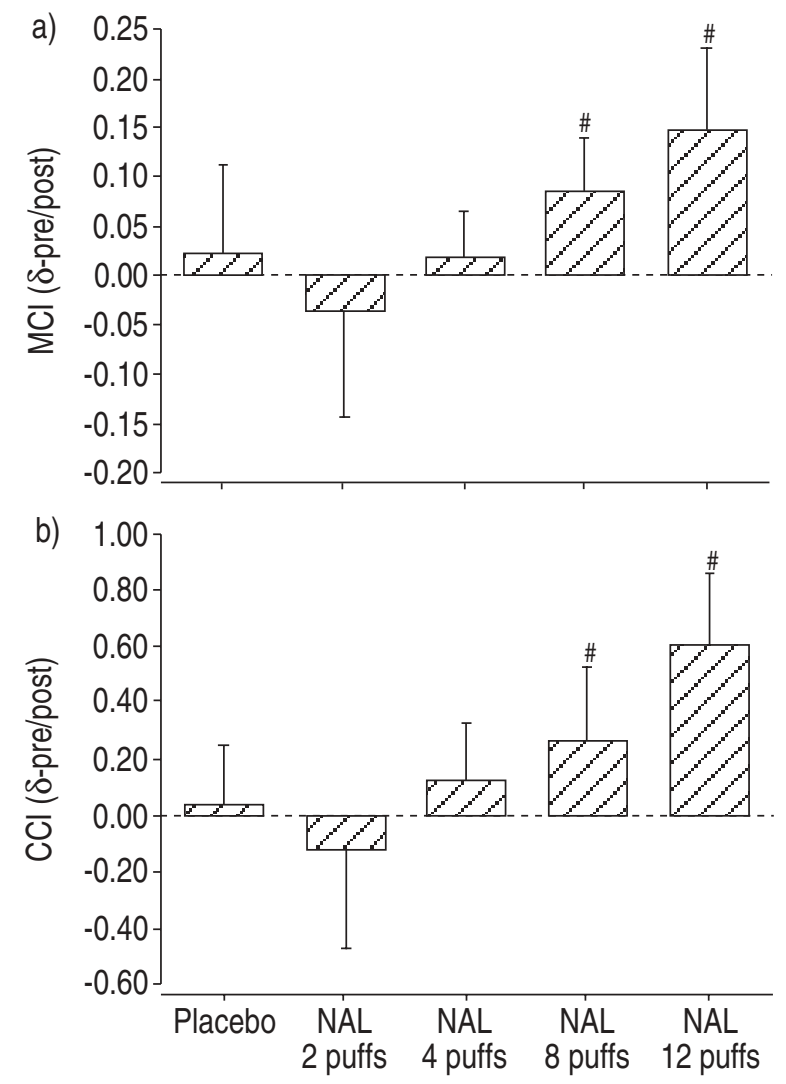

Fig. 2. - Nacystelyn (NAL) dose-response of a) mucociliary clearability index $(\mathrm{MCI})$ (change in MCI=1.62-(0.22 $\left.\times \log \mathrm{G}^{*} 1\right)-(0.77 \times$ $\tan \delta 1)$ ) and b) cough clearability index (CCI) (change in $\mathrm{CCI}=3.44-\left(1.07 \times \log \mathrm{G}^{*} 100\right)+(0.89 \times \tan \delta 100)$ as a function of the dose of NAL. MCI and CCI are derived from sputum viscoelastic data. MCI predicts the normalized clearance rate on frog palate ciliated epithelium and CCI predicts normalized clearance by airflow in a simulated cough machine. Data are illustrated as mean difference (pre/post) \pm SEM. ${ }^{\#}$ : statistically significant difference from placebo by paired t-test. 


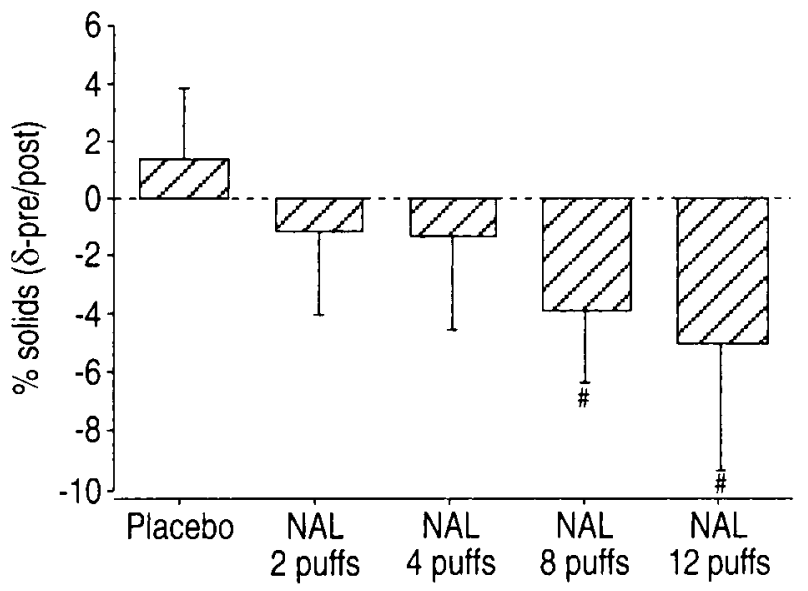

Fig. 3. - Nacystelyn (NAL) dose-response of sputum solids content. The change in sputum solids content (\% dry/wet weight) as a function of the delivered dose of NAL is shown. Data are illustrated as mean difference (pre/post) \pm SEM. \#. statistically significant difference from placebo by paired t-test.

filancemeter. The results indicate increasing elastic deformation with NAL, consistent with the decrease in $\log \mathrm{G}^{*}$. The increase in spinnability at 12 puffs of NAL was statistically significant $(\mathrm{p}=0.045)$.

Sputum electrolytelsolids content. There was a significant decrease in sputum solids content (fig. 3) or, in other words, an increase in sputum water content. The changes at eight and 12 puffs were highly significant $(\mathrm{p}=0.0009$ and $\mathrm{p}=0.0002$, respectively).

There was also a dose-dependent increase in chloride ion content with increasing NAL administration. The changes in chloride and sodium ion content at 12 puffs of NAL are illustrated in figure 4. Both ion contents increased with NAL administration in comparison with placebo $\left(\mathrm{p}=0.009\right.$ for $\mathrm{Cl}^{-}$and $\mathrm{p}=0.004$ for $\mathrm{Na}^{+}$). There was no change in either potassium or calcium content.

Sputum elastase activity. For all NAL concentrations, the assayed level of human neutrophil elastase in the sputum supernatant did not change significantly.

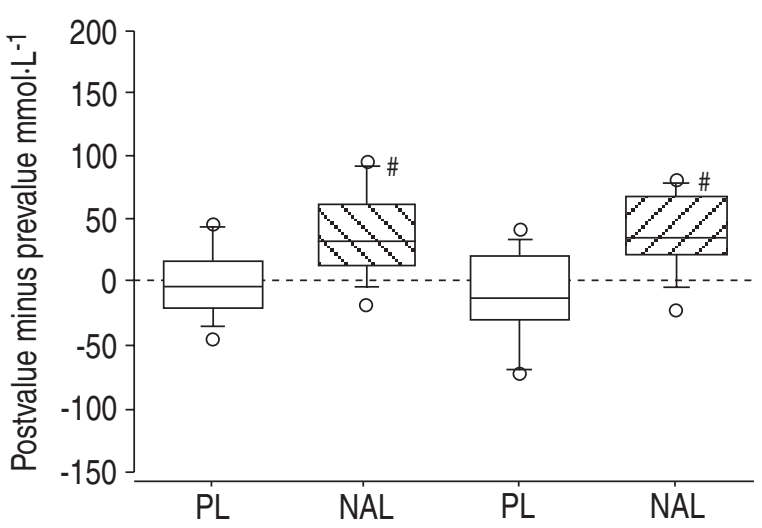

Fig. 4. - Sputum electrolyte changes after 12 puffs of placebo (PL) or $24 \mathrm{mg}$ (12 puffs) of Nacystelyn (NAL). A box plot (mean change and $95 \%$ confidence intervals $(\bigcirc)$ ) of sputum chloride $(\nabla)$ and sodium $(\square)$ contents NAL versus placebo $(\square)$ is shown. \#. statistically significant difference from placebo by paired t-test.

However, the elastase content in the sample sediment tended to decrease at eight and 12 puffs of NAL. The level of bronchial secretory inhibitor activity in the supernatant did not change with the dose of NAL.

\section{Study 2: 24-h monitoring study}

The age, sex, genotype, radiograph score, and respiratory characteristics of the patients at the preinclusion examination are summarized in table 4. Five of these patients, all recruited from the Academic Hospital-VUB, had an FEV1 of $<30 \%$. The main reasons that the investigator included them in the study was that they all regularly produced the large quantities of sputum required for analysis of the primary efficacy criteria in this study and the investigator considered that there were no undue safety concerns. These patients satisfied all the other inclusion and exclusion criteria; in particular, they all gave their informed written consent and were all able to clinically support the $\sim 11$-day washout period of

Table 4.-Baseline clinical and anthropometric data: 24-h monitoring study

\begin{tabular}{|c|c|c|c|c|c|c|c|c|c|}
\hline Patient & Sex & Age yrs & Genotype & $\begin{array}{c}\text { XRS } \\
\max 25\end{array}$ & $\begin{array}{c}\text { VC } \\
\% \text { pred }\end{array}$ & $\begin{array}{l}\text { FEV1 } \\
\% \text { pred }\end{array}$ & $\begin{array}{c}\text { Tiffenau } \\
\text { FEV1/VC } \%\end{array}$ & sRaw meas. & PEF meas. \\
\hline 1 & $\mathrm{M}$ & 21 & F508/F508 & 15 & 98 & 77 & 80 & 8.4 & 5.1 \\
\hline 2 & $\mathrm{M}$ & 22 & F508/F508 & 19 & 73 & 53 & 72 & 13.9 & 6.2 \\
\hline 3 & M & 28 & unknown & 17 & 77 & 41 & 53 & 17.0 & 5.1 \\
\hline 4 & $\mathrm{~F}$ & 17 & unknown & 14 & 81 & 54 & 68 & 6.6 & 5.2 \\
\hline 5 & $\mathrm{~F}$ & 12 & F508/- & 16 & 77 & 69 & 90 & 6.8 & 5.0 \\
\hline 6 & $\mathrm{M}$ & 25 & F508/F508 & 17 & 90 & 48 & 52 & 3.3 & 5.9 \\
\hline 7 & $\mathrm{~F}$ & 16 & F508/F508 & 8 & 41 & 24 & 58 & 5.2 & 1.4 \\
\hline 8 & $\mathrm{~F}$ & 31 & F508/F508 & 7 & 27 & 14 & 54 & 5.7 & 0.5 \\
\hline 9 & $\mathrm{M}$ & 18 & F508/F508 & 24 & 36 & 22 & 60 & 5.3 & 1.9 \\
\hline 10 & $\mathrm{M}$ & 26 & unknown & 6 & 58 & 38 & 66 & 5.0 & 6.9 \\
\hline 11 & $\mathrm{~F}$ & 22 & F508/F508 & 24 & 22 & 17 & 80 & 4.8 & 2.5 \\
\hline 12 & $\mathrm{~F}$ & 26 & F508/F508 & 9 & 36 & 23 & 62 & 6.2 & 4.6 \\
\hline
\end{tabular}

XRS: X-ray score; VC: vital capacity; FEV1: forced expiratory volume in one second; sRaw: specific airway resistance; PEF: peak expiratory flow; \% pred: percentage of predicted; M: male; F: female; meas.: the actual measured values as compared to $\%$ pred. 
antibiotics, bronchodilators, mucolytics and expectorant drugs from 3 days before and until the end of the study. Of these five patients, four regularly took inhaled mucolytics, three took inhaled bronchodilators, and only one took an oral antibiotic prior to their entry into the protocol. Hence, they were considered to be protocol deviations and kept for analysis in the study. The evolution of the symptomatology and the physical examination (tiredness, appetite, dyspnoea, general status) over the course of $24 \mathrm{~h}$, following inhalation of the test drug, was not statistically different between the two groups of patients. There were no important adverse events in either group.

Sputum rheological values. Figure 5a shows the principal index of mucus rigidity $\left(\mathrm{G}^{*}\right.$ in $\left.\mathrm{dyn} \cdot \mathrm{cm}^{-2}\right)$, as determined by magnetic rheometry at $1 \mathrm{rad} \cdot \mathrm{s}^{-1}$ and expressed on a logarithmic scale $\left(\log \mathrm{G}^{*} 1\right)$. The differences in $\log \mathrm{G}^{*}$ at $100 \mathrm{rad} \cdot \mathrm{s}^{-1}$, which were very similar, are illustrated in figure $5 \mathrm{~b}$. The maximum difference in $\log \mathrm{G}^{*} 1$ was $0.43 \log$ units (factor of 2.7 decrease on a linear scale), which occurred at $4 \mathrm{~h}$ after inhalation of NAL. In simple terms, the mucus became less rigid or more deformable with NAL
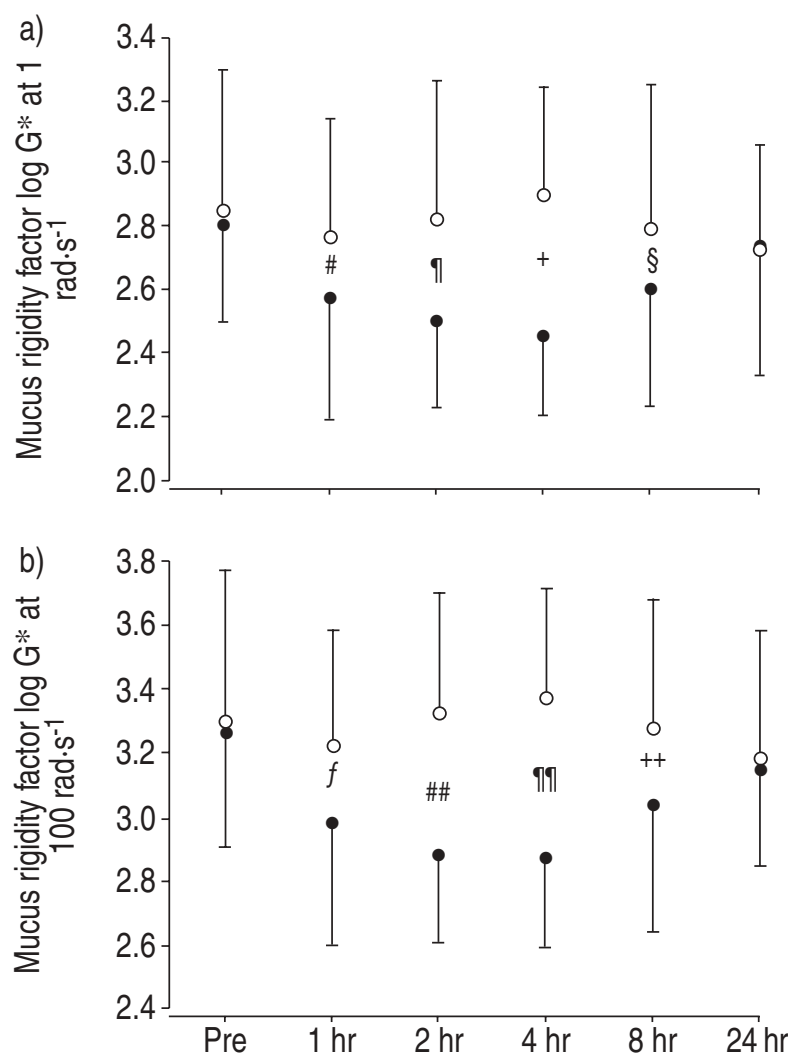

Fig. 5. - Time course of mucus rigidity using the sputum rigidity index a) at low frequency $\left(\log \mathrm{G}^{*}\right.$ at 1 radian $\left.(\mathrm{rad}) \cdot \mathrm{s}^{-1}\right)$ and b) at high frequency $\left(\log \mathrm{G}^{*}\right.$ at $\left.100 \mathrm{rad} \cdot \mathrm{s}^{-1}\right)$, as determined by magnetic rheometry versus time of sputum collection after inhalation of 12 puffs of placebo $(\bigcirc)$ or Nacystelyn $(\mathbf{O})$. Data are illustrated as mean $\pm \mathrm{SD}(\mathrm{N}=12)$. Data points statistically different from placebo are indicated by paired t-test values. ${ }^{\#}$ : $\mathrm{p}=0.033$; $\mathrm{p}=0.016 ;{ }^{+}: \mathrm{p}=0.0003 ;{ }^{\S}$ : nonsignificant; ${ }^{f}: \mathrm{p}=0.007 ;{ }^{\# \#}: \mathrm{p}=0.0004 ;{ }^{*}$ : $\mathrm{p}=0.0002 ;$ i+ $\mathrm{p}=0.029$. administration at $1,2,4$, and $8 \mathrm{~h}\left(\right.$ only $\left.100 \mathrm{rad} \cdot \mathrm{s}^{-1}\right)$. The net effect of these changes in sputum viscoelasticity is a projected benefit in clearability, based on predictions from model studies [25]. There was no apparent order-of-treatment effect (placebo first or NAL first). There was, however, some indication of a diurnal cycle of sputum viscoelasticity in the placebo data.

Solids and ion contentlelastase and inhibitor activity. There were no significant differences in the sputum solids content during NAL inhalation over the $24 \mathrm{~h}$ of the study. None of the measured sputum ion contents $(\mathrm{Na}, \mathrm{Cl}, \mathrm{K}, \mathrm{Ca})$ were found to vary significantly between NAL and placebo administration over the course of $24 \mathrm{~h}$. The assayed levels of human neutrophil elastase did not change significantly over the course of $24 \mathrm{~h}$, and there were no differences (either in supernatant or sediment) associated with NAL administration. There was also no change in bronchial secretory inhibitor in the sputum supernatant.

Particle size distribution. With the MDI device (Armstrong Laboratories) plus Volumatic spacer (Allen \& Hanburys), the respirable fraction (weight fraction of particles of diameter $<4.7 \mu \mathrm{m}$ ) was $9 \pm 1 \%$ or approximately one-tenth the nominal dose, measured on an Andersen Cascade Impactor (Andersen plc) at an airflow rate of $28.3 \mathrm{~L} \cdot \mathrm{min}^{-1}$. The deposition extended to several stages and was reproducible between runs. In addition, it was proven that the lung deposition of NAL from the MDI was uniform during the life of the inhaler (150 puffs).

\section{Discussion}

NAL inhalation in study 1 was well tolerated by all of the patients, and there were no acute changes in pulmonary function associated with NAL administration at any of the doses studied or with placebo inhalation. There were very few adverse events recorded (seven out of a total 50 study days) and none were serious. With the exception of cough and throat irritation in one patient, the adverse events can all be considered as transitory wheezing. Given the fact that the majority of the adverse events were associated with 12 puffs of the placebo, they can probably be attributed to the chlorofluorocarbon propellants of the MDI. This will not be a factor in the newer dry powder technology [28]. Long-term adverse events, or those which evolve more slowly (e.g. allergic reactions), are beyond the scope of the present studies.

Even allowing for the fact that detection of adverse events is difficult in CF patients because of preexisting lung damage, the lack of adverse events associated with NAL administration is consistent with the wide margin of safety indicated by prior toxicology studies conducted on dogs [29] and healthy human volunteers [12].

The baseline values of $\log \mathrm{G}^{*}$ (rigidity factor) of the sputum of these CF patients are high when compared with those for tracheal mucus from normal humans 
[30], or even smokers, with or without obstructive bronchitis [31]. However, the values are not dissimilar to the control values (placebo treatment group) obtained for $\mathrm{CF}$ patients in other studies involving magnetic rheometry analysis $[27,32,33]$. Similarly, the per cent solids content is also elevated over the normal range. This picture is consistent with the expectations for sputum rheology and composition in $\mathrm{CF}$, where a high content of proteins and deoxyribonucleic acid (DNA) of cellular origin is believed to add significantly to the cross-linking of the mucous gel network. The placebo rheological data (fig. 5) give some indication of a diurnal cycle of sputum viscoelasticity, which has not been reported previously.

In study 1, the rheological effect of NAL was determined at only a single time point $(\sim 30 \mathrm{~min}$ following drug inhalation). At this time point, only the acute effects of the drug in the central airways may have been measured. The dose-dependent decrease in mucus viscoelasticity $\left(\log G^{*}\right)$ can partly be attributed to the known mucolytic effect of disulphide bond disruption due to the ACC component $[5,6]$. The fact that there was also a dose-dependent decrease in solids content (increase in mucous gel hydration) suggests that the mechanism of action also involves increased chloride secretion to the epithelial lining fluid, accompanied by augmented transfer of sodium and water. This argument is reinforced by the finding of an increased content of chloride and sodium in the sputum samples after NAL administration. These ion content changes appear to involve an active ion transport process, rather than general dehydration, since there was no change in either potassium or calcium content.

The results of study 2, as illustrated by the significant changes in sputum viscoelasticity and spinnability, confirm the acute effect of NAL inhalation in $\mathrm{CF}$ patients on the important properties of airway mucus that relate to mucociliary and cough clearance. Furthermore, the present results demonstrate that these significant changes persist for $\geqslant 4 \mathrm{~h}$, and perhaps $8 \mathrm{~h}$ after administration of aerosol. The peak effect appears to occur $\sim 4 \mathrm{~h}$ after inhalation, consistent with a 4-6-h clearance half-time of mucus from the airways [14, 15]. The timing of the rheological changes indicates a good profile for a mucolytic drug, an effect lasting long enough to clear the majority of the mucus from the lung [16]. Based on these results, a twice- or three-times daily inhalation of NAL, at a 24-mg delivered dose, would probably be an appropriate target range for further clinical testing [34].

In study 2, the significant changes in sputum viscoelasticity $\left(\log \mathrm{G}^{*}\right)$ were not accompanied by significant changes in sputum solids content or $\mathrm{Cl}^{-}$ $\mathrm{Na}^{+}$contents, as was the case in study 1 . The reason for this discrepancy is unknown.

The value of the respirable fraction obtained in the present study was similar to that observed by HARDY et al. [19] in six healthy volunteers. The study of HARDY et al. [19] also demonstrated that the lung deposition was similar in central, intermediate and peripheral lung compartments in healthy volunteers. The relatively small values of standard deviations obtained in vitro and in vivo show that lung deposition from the MDI is reproducible and can be assumed to be $10 \%$. Since each actuation delivers $2 \mathrm{mg}$ of NAL, 12 puffs from the inhaler are needed to obtain the lung deposition dose of $2.4 \mathrm{mg}$ of NAL. This equates to the inhalation of one 8-mg dry powder inhaler capsule, where the lung deposition is $\sim 30 \%$.

In summary, administration of a single dose of Nacystelyn by metered-dose inhaler, $\leqslant 12$ puffs $(24 \mathrm{mg})$ in patients with mild-to-moderate cystic fibrosis lung dysfunction, was well tolerated and free of any adverse effects due to the active ingredient. Although there was no acute change in pulmonary function or any clinical indicator, there were significant changes in sputum rheology and hydration predictive of improved airway mucus clearance. Over $24 \mathrm{~h}$, there were no adverse events associated with administration of $24 \mathrm{mg}$ of Nacystelyn by metered-dose inhaler. Potentially beneficial changes in sputum rheology lasting $\leqslant 8 \mathrm{~h}$ were observed. The results of these initial studies justify further testing of this drug in cystic fibrosis patients.

Acknowledgements. The authors gratefully
acknowledge the skilled editing assistance of S.G. Cochrane.

\section{References}

1. National Institutes of Health (NIH)/National Heart, Lung Blood Institute. Facts About Cystic Fibrosis. Bethesda, MD, U.S. Dept of Health and Human Services, 1995. NIH Publication No. 95-3650.

2. Mearns MB. Cystic fibrosis: The first 50 years. A review of the clinical problems and their management. In: Dodge JA, Brock DJH, Widdicombe JW, eds. Cystic Fibrosis - Current Topics. Vol. 1. New York, Wiley \& Sons, 1993; pp. 217-250.

3. Quinton PM. Physiological basis of cystic fibrosis: A historical perspective. Physiol Rev 1999; 79: Suppl. 1, S3-S22.

4. Cantin A. Cystic fibrosis lung inflammation: early, sustained and severe. Am J Respir Crit Care Med 1998; 151: 939-940.

5. Marriott C, Ingham S, Coffiner M, Fossion J, Maes P. Determination of the mode of action of a novel mucolytic agent Nacystelyn. Eur Respir J 1993; 6: Suppl. 17, 438s.

6. App EM, Tomkiewicz RP, King M, et al. New MDI mucolytic Nacystelyn (NAL) compared with $\mathrm{N}$-Acetylcysteine (NAC) and other reducing agents in human sputum rheology and bronchial secretion inhibitor (BSI) activity in vitro. Eur Respir J 1992; 5: Suppl. 15, 129s.

7. Dasgupta B, King M. Reduction in viscoelasticity of cystic fibrosis sputum in vitro with combined treatment by Nacystelyn and rhDNase. Pediatr Pulmonol 1996; 22: 161-166.

8. Tomkiewicz RP, App EM, De Sanctis GT, et al. A comparison of a new mucolytic $N$-acetylcysteine L-lysinate with $N$-acetylcysteine: airway epithelial function and mucus changes in dog. Pulmonol Pharmacol 1995; 8: 259-265. 
9. Tomkiewicz RP, App EM, Coffiner M, Fossion J, Maes P, King M. Mucolytic treatment with $N$-acetylcysteine L-lysinate metered dose inhaler in dogs: airway epithelial function changes. Eur Respir $J$ 1994; 7: 81-87.

10. King M, Tomkiewicz RP, Shao A, App EM, Coffiner M, Maes P. Effects of Nacystelyn and lysine aerosols in chloride-free medium on tracheal epithelial mucociliary function in normal dogs. Eur Respir J 1996; 9: Suppl. 23, 188s.

11. Sudo E, King M. Effect of lysine on tracheal mucus rheology and secretion in mice. Am J Respir Crit Care Med 1999; 159: A686.

12. Duchatelet $\mathrm{P}$, Songore D, Ravez P, Robience YJ. Influence du lysinate de $N$-Acetylcysteine en aérosol doseur sur les paramètres spirographiques. Acta Therapeutica 1987; 13: 579-586.

13. Vanderbist $\mathrm{F}$, Maes $\mathrm{P}$, Nève J. In vitro comparative assessment of antioxidant activity of Nacystelyn against three reactive oxygen species. Arzneimittelforschung 1996; 46: 783-788.

14. Nagy AM, Vanderbist F, Parij N, Maes P, Fondu P, Nève J. Effects of the mucoactive drug Nacystelyn on the respiratory burst of human blood polymorphonuclear neutrophils. Pulmonol Pharmacol Ther 1997; 10: 287-292.

15. Gillissen A, Jaworska M, Orth M, et al. Nacystelyn and $N$-acetylcysteine augment cellular antioxidant defense in two distinctive ways. Respir Med 1997; 81: 159-168.

16. Mulier B, Watchorn T, Donaldson K, MacNee W. The comparative ability of thiol compounds to protect against hydrogen peroxide-induced injury in airway epithelial cells. Thorax 1997; 52: Suppl. 6, A56.

17. App EM, Tomkiewicz RP, King M, et al. Thio-group carrying mucolytic agents inactivate protease such as human neutrophil elastase (HNE) in vitro. Am Rev Respir Dis 1993; 147: A673.

18. App EM, Hochstrasser K, Tomkiewicz RP, et al. Do $\mathrm{SH}$ group carrying reducing agents affect the protease-antiprotease balance in bronchial secretions? Eur Respir J 1993; 6: Suppl. 17, 438s.

19. Hardy JG, Everard M, Coffiner M, Fossion J. Lung deposition of a Nacystelyn metered dose inhaler formulation. J Aerosol Med 1993; 6: 37-44.

20. Preparation for inhalation aerodynamic assessment of fine particles (section 2.9.18). In: European Pharmacopoeia. 3rd Edn. Strasbourg, France, Council of Europe, 1997.

21. Brasfield D, Hicks G, Soong S, Peters J, Tiller R. Evaluation of scoring system of the chest radiograph in cystic fibrosis: A collaborative study. $\mathrm{Am}$ J Roentgenol 1980; 134: 1195-1198.

22. Puchelle E, Tournier JM, Zahm JM, Sadoul P.
Rheology of sputum collected by a simple technique limiting salivary contamination. J Lab Clin Med 1984; 103: 347-353.

23. King M, Macklem PT. Rheological properties of microliter quantities of normal mucus. J Appl Physiol 1977; 42: 797-802.

24. King M. Magnetic microrheometer. In: Braga PC, Allegra L, eds. Methods in Bronchial Mucology. New York, Raven Press, 1988; pp. 73-83.

25. King M. Role of mucus viscoelasticity in cough clearance. Biorheology 1987; 24: 589-597.

26. Puchelle E, Zahm JM, Duvivier C. Spinnability of bronchial mucus: Relationship with viscoelasticity and mucus transport properties. Biorheology 1983; 20: $239-249$.

27. Tomkiewicz RP, App EM, Zayas JG, et al. Amiloride inhalation therapy in cystic fibrosis: Influence on ion content, hydration and rheology of sputum. Am Rev Respir Dis 1993; 148: 1002-1007.

28. Vanderbist F, Wery B, Moyano-Pavon I, Moës AJ. Optimization of a dry powder inhaler formulation of Nacystelyn, a new mucoactive agent. $J$ Pharm Pharmacol 1999; 51: 1229-1234.

29. Van Cantfort J. Inhalation toxicology study reports, with Nacystelyn (NAL) 28 days and 182 days repeated dose in dogs. Advanced Technology Corporation (ATC) Projects D-NAL-28D-96, D-NAL-182D-96, 1997 (internal report, University of Liege, Liege, Belgium).

30. Jeanneret-Grosjean A, King M, Michoud MC, Lioté $\mathrm{H}$, Amyot R. Sampling technique and rheology of human bronchial mucus. Am Rev Respir Dis 1988; 137: 707-710.

31. Zayas JG, Man GCW, King M. Tracheal mucus rheology in patients undergoing diagnostic bronchoscopy: Interrelations with smoking and cancer. $\mathrm{Am}$ Rev Respir Dis 1990; 141: 1107-1113.

32. App EM, King M, Helfesrieder R, Köhler D, Matthys $\mathrm{H}$. Acute and long term amiloride inhalation in cystic fibrosis lung disease: A rational approach to cystic fibrosis therapy. Am Rev Respir Dis 1990; 141: 605612.

33. Knowles MR, Church NL, Waltner WE, et al. A pilot study of aerosolized amiloride for the treatment of cystic fibrosis lung disease. N Engl J Med 1990; 322: $1189-1194$.

34. Laboratoires SMB. Protocol NAL-96-12-RD: Randomised multicentric double-blind study of the efficacy and tolerability of two doses of Nacystelyn versus placebo in patients suffering from cystic fibrosis treated for at least 6 months. Brussels, Belgium, Internal draft report of September 15, 2000. 